\title{
KHẢO SÁT ĐỂ THI TUYỂN SINH ĐẠI HỌC MÔN TIẾNG PHÁP GIAI ĐOẠN 2005-2014
}

\author{
Nguyễn Việt Quang*
}

Khoa Ngôn ngũ và Văn hóa Pháp, Trường Đại học Ngoại ngũu, ĐHQGHN, Phạm Văn Đồng, Cầu Giấy, Hà Nội, Việt Nam

Nhận bài ngày 13 tháng 06 năm 2016

Chỉnh sửa ngày 16 tháng 12 năm 2016; Chấp nhận đăng ngày 06 tháng 01 năm 2017

Tóm tắt: Để góp phần tổ chức tốt kỳ thi “đánh giá năng lực” phục vụ công tác tuyển sinh trong giai đoạn mới, cần thiết phải nghiên cứu các đề thi tuyển sinh đại học trong những năm trước. Bài viết tập trung vào môn tiếng Pháp giai đoạn 2005-2014 (10 đề). Mục đích của nghiên cứu là tìm ra các điểm mạnh cũng như những hạn chế trong cấu trúc và nội dung của các đề thi trên. Tác giả bắt đầu bằng việc xác định các lĩnh vực ngôn ngữ và giao tiếp của các câu hỏi-tiểu mục, sau đó tiến hành phân tích nội dung chính của từng lĩnh vực, cuối cùng đưa ra những đề xuất phục vụ cho việc thiết kế và biên soạn đề thi tuyển sinh môn tiếng Pháp.

Từ khóa: thi tuyển sinh, lĩnh vực kiến thức, đánh giá, đề thi tiếng Pháp

\section{1. Đặt vấn đề}

Từ năm 2015, theo chủ trương chung của Đại học Quốc gia Hà Nội, Trường Đại học Ngoại ngữ đã tiến hành tuyển sinh thông qua kỳ thi “đánh giá năng lực"(1). Cũng như các môn ngoại ngữ khác, đề thi môn tiếng Pháp được thiết kế theo một cấu trúc mới và từ năm 2016 thực hiện trên máy tính. Một công việc dù mới đến đâu cũng mang tính kế thừa. Để có được một công cụ đánh giá tốt, chúng tôi thấy cần thiết khảo sát các đề thi tuyển sinh đại học giai đoạn trước đó do Bộ Giáo dục và Đào tạo chỉ đạo biên soạn.

Chúng tôi tập trung vào môn tiếng Pháp giai đoạn 2005-2014 với tổng số là 10 đề. Là sản phẩm của một đội ngũ chuyên gia giàu kinh nghiệm, các đề thi này có thể coi là khuôn mẫu trên bình diện ngôn ngữ. Tuy vậy chúng tôi thấy vẫn còn một số điểm bất hợp lý thể

\footnotetext{
* ĐT.: 84-1684969898, Email: nvquang74@yahoo.fr

${ }^{1}$ http://vnu.edu.vn/ttsk/?C2097/N18032/Thong-tin-xettuyen-dai-hoc-chinh-quy-nam-2015-cua-dHQGHN.htm http://vnu.edu.vn/ttsk/?C1667/N18878/Thong-tinve-ky-thi-danh-gia-nang-luc-tuyen-sinh-vao-dai-hocchinh-quy-nam-2016-cua-dHQGHN.htm
}

hiện ở những mất cân đối trong cấu trúc đề thi và trong nội dung của các lĩnh vực kiến thức. Mục đích của nghiên cứu là làm nổi bật các điểm mạnh cũng như các điểm yếu của các đề thi trên. Phương pháp sử dụng là thống kê, xếp loại sau đó phân tích rút ra kết luận. Chúng tôi bắt đầu bằng việc xác định các lĩnh vực ngôn ngữ và giao tiếp của các câu hỏi-tiểu mục $(\mathrm{CT})$, sau đó tiến hành phân tích nội dung chính của từng lĩnh vực, cuối cùng đưa ra một số đề xuất phục vụ cho việc thiết kế và biên soạn đề thi tuyển sinh môn tiếng Pháp trong giai đoạn mới.

\section{Xác định các lĩnh vực kiến thức}

Tất cả các đề thi, trừ năm 2005, bao gồm $80 \mathrm{CT}$. Câu hỏi sử dụng hầu hết là dạng đa lựa chọn; chỉ có đề thi năm 2005 còn giữ một số câu hỏi truyền thống yêu cầu thí sinh viết câu trả lời. Bài thi được thực hiện trên giấy.

Về cách trình bày, các $\mathrm{CT}$ được đánh số liên tiếp và không chỉ rõ lĩnh vực đánh giá. Ở bài đọc hiểu, thí sinh phải đọc một văn bản và trả lời 10 câu hỏi về nội dung của bài, nhưng vị trí của bài đọc thay đổi giữa các năm: lúc thì 
ở đầu $(2006,2007,2008,2010)$, khi thì ở cuối (năm 2009, 2011, 2012, 2013, 2014), khi thì ở giữa (2005). Ngoài ra còn một bài kiểm tra kiến thức từ vựng dưới dạng điền từ, vị trí cũng không cố định. Cách trình bày như vậy cho cảm giác là các đề thi không được biên soạn theo một cấu trúc (architecture) định trước.

Nhiệm vụ đầu tiên của chúng tôi là tiến hành xác định các lĩnh vực kiến thức đã được đề cập. Sau khi phân tích chi tiết, chúng tôi xếp các $\mathrm{CT}$ thành bốn lĩnh vực: ngữ pháp, từ vựng, đọc hiểu và ngôn ngữ nói (ngôn ngữ được sử dụng trong giao tiếp nói). Cần chú ý là trong một $\mathrm{CT}$ luôn có sự tham gia kiến thức của nhiều lĩnh vực, nhưng luôn có một lĩnh vực nổi trội do ý đồ của người biên soạn. Chúng tôi sẽ lần lượt xem xét từng lĩnh vực.

\subsection{Ngũ pháp}

Thuật ngữ "ngữ pháp" có nhiều nghĩa. Tù điển ngôn ngũ học nêu 4 định nghĩa (Dubois, 1994). Ở đây, chúng tôi sử dụng định nghĩa thứ ba: "ngữ pháp là sự mô tả các hình vị ngũ̃ pháp (quán từ, liên từ, giới từ, vv.) và các quy tắc chi phối hoạt động của các hình vị trong câu. Ngữ pháp không bao gồm các hình vị từ vựng (danh từ, tính từ, động từ, trạng từ chỉ cách thức)". Tất cả các $\mathrm{CT}$ đáp ứng tiêu chí này được chúng tôi xếp vào mục «ngữ pháp». Ví dụ như hai CT dưới đây :

- $76(05)^{(2) / 4}$ Sylvie est partie de ...... elle à cinq heures et demie ..... 77(05) son amie Nathalie." Từ cần tìm để điền vào câu trên là các giới từ "chez"và "avec". Đó là hai hình vị ngữ pháp.

- 71 (05) "dans / êtes / est-ce que / ne / née ? / où / Pourquoi / revenez plus / le village

${ }^{2}$ Số đầu tiên chỉ "số" của câu hỏi tiểu mục, số trong ngoặc đơn chỉ "năm". 76(05) được đọc là câu tiểu mục số 76 trong đề thi năm 2005.
/ vous / vous". Ở đây thí sinh phải sắp xếp lại các từ thành một câu đúng; yêu cầu này cũng thuộc lĩnh vực ngữ pháp.

\subsection{Tù̀ vựng}

Nếu các hình vị ngữ pháp tạo thành một tập hợp đóng (ensemble fermé) thì các thành tố từ vựng thuộc về một tập hợp mở. Các CT kiểm tra kiến thức thuộc tập hợp mở được chúng tôi xếp vào mục «từ vựng». Thí dụ:

31(05) La femme de ménage a fait le bureau. $\rightarrow$ La femme de ménage ........ le bureau.

32(05) Il fera un bon mari. $\rightarrow$ Il $\ldots \ldots \ldots$. un bon mari.

Yêu cầu ở đây là thay thế động từ "faire" bằng một động từ phù hợp. Các động từ có khả năng đảm nhiệm công việc này là "essuyer" và "être", chúng thuộc lĩnh vực "từ vựng".

Tuy nhiên, cần lưu ý một yếu tố có thể vừa thuộc lĩnh vực ngữ pháp, vừa thuộc lĩnh vực từ vựng. Thí dụ “sortir”, với tư cách động từ (đi ra khỏi một địa điểm), từ này thuộc lĩnh vực "từ vựng", nhưng việc sử dụng thời thể phù hợp trong từng hoàn cảnh cụ thể thì lại thuộc lĩnh vực "ngữ pháp". Do đó, chúng tôi xếp vào lĩnh vực "ngữ pháp" các $\mathrm{CT}$ như 11 (05): "J'aimerais que tu (sortir) le chien. Je n'ai pas le temps. Je dois téléphoner à Sophie" (ở đây thí sinh phải tìm cách chia động từ phù hợp).

\section{3. Đọc hiểu}

Việc kiểm tra "đọc hiểu" dễ được nhận biết vì nó được trình bày thống nhất trong tất cả các đề: một bài đọc đi kèm các câu hỏi về nội dung. Thực ra, việc đọc hiểu còn diễn ra ở tất cả $\mathrm{CT}$ của đề thi, bởi lẽ để có thể tìm ra đáp án (từ vựng hay ngữ pháp...), thí sinh cần phải 
hiểu được ý nghĩa của câu. Ở đây, chúng tôi chỉ quan tâm đến loại đọc hiểu trong văn bản.

\subsection{Ngôn ngũ nói trong tình huống}

Nội dung kiểm tra ở đây không phải là giao tiếp mặt đối mặt, mà là ngôn ngữ được sử dụng trong giao tiếp nói. Trong nhiều đề thi, có những CT như:

27 (07) Pierre: - C'est de ta faute ! Guy: -........ (Non, je n'y suis pour rien.) ${ }^{(3)}$

31(07) Lorsque vous prenez congé, votre ami vous dit :.... (Dommage que tu doives partir !)

Câu đầu là một bài hội thoại khuyết, thí sinh phải điền vào chỗ trống bằng một phát ngôn đúng. Câu sau là một tình huống giao tiếp đòi hỏi thí sinh phải có hành vi ngôn ngữ phù hợp. Chúng tôi coi mục đích của các CT này là kiểm tra kiến thức ngôn ngữ nói trong tình huống.

Dựa trên các tiêu chí trên, chúng tôi đã tiến hành thống kê các $\mathrm{CT}$ của từng đề thi, kết quả (số lượng = tỷ lệ phần trăm) như sau:

Bảng 1. Phân bố các lĩnh vực kiến thức

\begin{tabular}{|c|c|c|c|c|}
\hline Năm & Ngũ pháp & Từ vựng & Đọc hiểu & $\begin{array}{c}\text { Ngôn ngữ } \\
\text { nói trong } \\
\text { tình huông }\end{array}$ \\
\hline 2005 & $68=75,50 \%$ & $12=13,30 \%$ & $5=5,60 \%$ & $5=5,60 \%$ \\
\hline 2006 & $51=63,75 \%$ & $15=18,75 \%$ & $8=10,00 \%$ & $6=7,50 \%$ \\
\hline 2007 & $30=37,50 \%$ & $26=32,50 \%$ & $20=25,00 \%$ & $4=5,00 \%$ \\
\hline 2008 & $36=45,00 \%$ & $19=23,75 \%$ & $20=25,00 \%$ & $5=6,25 \%$ \\
\hline 2009 & $37=46,25 \%$ & $29=36,25 \%$ & $10=12,50 \%$ & $4=5,00 \%$ \\
\hline 2010 & $47=58,75 \%$ & $19=23,75 \%$ & $10=12,50 \%$ & $4=5,00 \%$ \\
\hline 2011 & $43=53,75 \%$ & $23=28,75 \%$ & $10=12,50 \%$ & $4=5,00 \%$ \\
\hline 2012 & $45=56,25 \%$ & $20=25,00 \%$ & $10=12,50 \%$ & $5=6,25 \%$ \\
\hline 2013 & $42=52,50 \%$ & $23=28,75 \%$ & $10=12,50 \%$ & $5=6,25 \%$ \\
\hline 2014 & $46=57,50 \%$ & $21=26,25 \%$ & $10=12,50 \%$ & $3=3,75 \%$ \\
\hline $\begin{array}{c}\text { Tổng } \\
810=100 \%\end{array}$ & $445=54,94 \%$ & $207=25,55 \%$ & $113=13,95 \%$ & $45=5,56 \%$ \\
\hline
\end{tabular}

Bảng tổng hợp cung cấp nhiều thông tin thú vị. Theo chiều dọc, bảng 1 cho thấy

${ }^{3}$ Mỗi CT đều có 4 lựa chọn, chúng tôi chỉ nêu "đáp án" (không nêu 3 lựa chọn còn lại). có sự ổn định tương đối trong các cột 4 và 5, nhưng ở các cột ngũ pháp và tù vựng có sự mất cân đối lớn. Ví dụ, số câu hỏi tù vựng trong đề thi năm 2005 chưa bằng một nửa của các năm 2007, 2009. Điều này cho thấy các đề thi không được biên soạn theo một sự phân chia nội dung thống nhất, nhất là giữa các phần tì vưng và ngũ pháp. Theo hàng ngang, ta cũng thấy có sự mất cân đối. Thí dụ, số câu hỏi kiểm tra kiến thức ngôn ngữ vượt xa số câu hỏi đánh giá kỹ năng: phần ngôn ngũ nói trong tình huống tính trung bình chiếm chưa đến $6 \%$ tổng số các $\mathrm{CT}$. Dưới đây, chúng tôi sẽ nghiên cứu nội dung của từng lĩnh vực.

\section{Phân tích nội dung các lĩnh vực}

\subsection{Ngũ pháp}

Theo cách phân chia truyền thống, ngữ pháp bao gồm từ pháp (morphologie) và cú pháp (syntaxe). Từ pháp tiếng Pháp nghiên cứu 9 loại từ, trong đó có: quán từ, tính từ tính chất, tính từ xác định, đại từ, động từ, trạng từ, giới từ, liên từ. Cú pháp quan tâm đến hoạt động của các hình vị trong câu. Sự phân bố các nội dung trên trong các đề thi như bảng dưới.

Như vậy trong lĩnh vực ngữ pháp (với tổng số $445 \mathrm{CT}$ ), nhiều nhất là cú pháp (24,04\%) và động tù̀ (21,35\%). Vị trí thứ hai là của đại tù và giới tù̀ (16,85\% và $13,48 \%)$. Tính tù chiếm vị trí cuối cùng với 1,35\%. Cú pháp có vai trò quan trọng bậc nhất vì nó bao trùm lên toàn bộ câu, tiếp đến là động từ được coi là trụ cột của mệnh đề và luôn gắn với nhiều hiện tượng ngữ pháp như thức (mode), thời (temps), chúng tôi thấy dành cho chúng một tỷ lệ cao là điều hợp lý.

Nhưng có một sự mất cân đối trong ba từ loại: giới tù̀ chiếm tỷ lệ khá cao $(13,48 \%)$, trong khi đó, quán tù và tính tù xác định có vị 
trí thấp $(2,02 \%$ và $2,25 \%)$. Ta biết rằng giới từ chỉ dùng để cấu tạo các bổ ngữ và bị chi phối bởi động từ đi trước hoặc danh từ đi sau nó. Vai trò như vậy không quá quan trọng để từ loại này giữ vị trí thứ 3 trước rất xa quán từ và tính từ xác định (adjectif déterminatif). Cần chú ý là quán từ bao gồm ba tiểu loại: xác định, không xác và bộ phận (défini, indéfini, partitif), và tính từ xác định bao gồm sáu tiểu loại: chỉ số, sở hữu, chỉ định, không xác định, nghi vấn và quan hệ (adjectif numéral, possessif, démonstratif, indéfini, interrogatif et relatif). Các tiểu loại này cũng cần được quan tâm đầy đủ trong đề thi.

Bảng 2. Nội dung ngữ pháp thức phân tù và thức gérondif (Grévisse, 2007). Liệu các nội dung trên có được đề cập với một tỷ lệ cân đối trong các đề thi ? Sau khi khảo sát, chúng tôi thấy rằng thức trục thuyết (indicatif) có tỷ lệ CT cao nhất $(53,68 \%)$; thức này hiện diện trong tất cả các năm, nhưng phân bố không đều : năm cao nhất có 9 CT (2006) năm thấp nhất có 2 CT (2007). Về các thời, theo thống kê của chúng tôi 7 trên 8 thời của thức này đã được đề cập, nhưng có một sự mất cân bằng lớn về số lượng: thời présent xuất hiện 3 lần; thời passé composé : 14 lần; thời imparfait: 9 lần; thời plus-que-parfait: 7 lần; thời futur simple: 4 lần; thời futur

\begin{tabular}{|c|c|c|c|c|c|c|c|c|c|}
\hline Năm & $\begin{array}{l}\text { Quán } \\
\text { từ }\end{array}$ & $\begin{array}{l}\text { Tính } \\
\text { từ tính } \\
\text { chất }\end{array}$ & $\begin{array}{c}\text { Tính } \\
\text { từ xác } \\
\text { định }\end{array}$ & Đại từ & $\begin{array}{l}\text { Động } \\
\text { từ }\end{array}$ & $\begin{array}{c}\text { Trạng } \\
\text { từ }\end{array}$ & Giới từ & Liên từ & Cú pháp \\
\hline 2005 & 7 & & 2 & 4 & 21 & 4 & 9 & 1 & 20 \\
\hline 2006 & & 1 & 2 & 4 & 9 & 9 & 7 & 5 & 14 \\
\hline 2007 & & & & 4 & 4 & 2 & 8 & 1 & 11 \\
\hline 2008 & 1 & & 1 & 7 & 6 & 2 & 4 & 3 & 12 \\
\hline 2009 & & & & 6 & 6 & 3 & 6 & 5 & 11 \\
\hline 2010 & & 1 & & 10 & 10 & 5 & 7 & 7 & 7 \\
\hline 2011 & & & 1 & 10 & 9 & 6 & 5 & 4 & 8 \\
\hline 2012 & & & 3 & 10 & 10 & 2 & 6 & 6 & 8 \\
\hline 2013 & & 3 & 1 & 9 & 10 & 3 & 4 & 5 & 7 \\
\hline 2014 & 1 & 1 & & 11 & 10 & 3 & 4 & 7 & 9 \\
\hline $\begin{array}{c}\text { Tổng } 445 \\
=100 \%\end{array}$ & $\begin{array}{c}9= \\
2,02 \%\end{array}$ & $\begin{array}{c}6= \\
1,35 \% .\end{array}$ & $\begin{array}{c}10= \\
2,25 \%\end{array}$ & $\begin{array}{c}75= \\
16,85 \%\end{array}$ & $\begin{array}{c}95= \\
21,35 \%\end{array}$ & $\begin{array}{c}39= \\
8,76 \%\end{array}$ & $\begin{array}{c}60= \\
13,48 \%\end{array}$ & $\begin{array}{c}44= \\
9,89 \%\end{array}$ & $\begin{array}{c}107= \\
24,04 \%\end{array}$ \\
\hline
\end{tabular}

Nếu nhìn theo từng năm thì năm nào cũng có ô trống: 2007 và 2009 có số ô trống cao nhất (3 ô) ; như vậy một số nội dung ngũ̃ pháp đã bị bỏ qua. Đối với những từ loại xuất hiện trong tất cả các năm, cũng cần phải lưu ý vì chúng bao gồm rất nhiều tiểu loại. Lấy động từ làm ví dụ : có nội động từ và ngoại động từ, trong vận hành động từ luôn gắn với « thời » và « thức ». Trong tiếng Pháp có 7 thức: thức trục thuyết, thức điều kiện, thức chủ quan, thức mệnh lệnh, thức nguyên thể, antérieur: 2 lần; thời futur proche: 2 lần. Đáng chú ý là thời quá khứ gần (passé récent: venir de + infinitif) đã hoàn toàn bị bỏ quên. Theo chúng tôi, những mất cân đối như vậy cần tránh trong kỳ thi đánh giá năng lực sắp tới.

\subsection{Tù vựng}

Theo bảng thống kê ở trên, từ vựng chiếm trung bình một phần tư nội dung của mỗi đề. Việc đánh giá mảng kiến thức này được tiến hành, hoặc trong các CT riêng lẻ, hoặc trong một bài khóa ngắn, và về ba khía cạnh của 
từ là : từ vựng học, ngũ̃ nghĩa và chính tả (lexicologique, sémantique et orthographique).

- Về khía cạnh từ vựng học, các CT kiểm tra kiến thức về cấu tạo từ và nghĩa của từ trong ngôn ngữ: từ cùng họ, từ đồng nghĩa, từ trái nghĩa. Ví dụ:

5(13) Paul a participé aux épreuves de natation sportive. Le nom natation vient du verbe -------. (napper nager naturaliser naviguer)

41(13) Nous allons explorer 1'Espagne l'été prochain. Le synonyme du verbe explorer est --------. (rencontrer découvrir inviter ouvrir)

36(14) Le Vietnam commence à produire des vins de bonne qualité. Le contraire du verbe produire est ------. (conserver consommer consacrer consentir)

- Về khía cạnh ngữ nghĩa, các CT yêu cầu thí sinh tìm từ phù hợp để điền vào một chỗ trống trong câu. Nghĩa ở đây được đề cập trong một bối cảnh cụ thể, thí sinh phải dựa vào tất cả các từ trong câu để đưa ra câu trả lời đúng. Ví dụ:

59(14) Patricia était bonne en maths mais ----- en littérature. (meilleur fort nulle capable).

22(06) Elle est très riche mais elle n'a ni famille ni amis. Elle est vraiment une -------. (pauvre femme femme pauvre femme riche femme désagréable)

- Về khía cạnh chính tả, các CT kiểm tra việc hợp giống, hợp số (orthographe grammticale) giữa các từ. Ví dụ:

7(14) Elise vient d'acheter à ses cousines deux écharpes--------. (oranges gris clair bleu marines vert)

18(14) Justine est très jolie avec ses -------- cheveux -------. (longues=blondes blonds=longs longs=blonds longs=blondes).

Một câu hỏi đặt ra là: số lượng tù được đưa ra kiểm tra là bao nhiêu, tần sốxuất hiện như thế nào, nghĩa của tù có thông dụng không ? Để có câu trả lời, chúng tôi đã tiến hành thống kê các đơn vị từ vựng. Trước tiên là các từ mà thí sinh phải tìm để điền vào chỗ trống trong các $\mathrm{CT}$ và trong các bài khóa dùng để kiểm tra mảng kiến thức này. Đối với các $\mathrm{CT}$ kiểm tra kiến thức từ vựng học thì cả từ trong câu hỏi (déclencheur) và từ trả lời đều được tính. Thí dụ: 44(14) Avec les nouvelles technologies, nous pouvons explorer le fond des mers. Le contraire du nom "fond" est------. (espace surface trace préface). Từ "fond" trong câu hỏi và từ "surface" cần phải điền vào câu trả lời, cả hai đều được đưa vào danh sách. Sau khi tổng hợp kết quả, chúng tôi có bốn nhận xét sau:

• Tổng số đơn vị từ vựng thuộc nội dung kiểm tra này là 273 ; bắt đầu danh sách theo thứ tự $\mathrm{ABC}$ là absolument (09), kết thúc là vrai (12). Phân bố như sau: 74 danh từ, 90 động từ, 88 tính từ và 21 trạng từ, như vậy có sự cân bằng giữa 4 loại từ. Tần số xuất hiện nhiều nhất (3 lần) là các tính từ gentil, meilleur và prochain. (Xem Phụ lục)

- Các tác giả đã chú ý đến các cụm từ cố định. Thí dụ: En avoir assez (07), avoir l'air (05), en avoir marre (07), avoir tout son temps(07), larmes de crocodile(09). Các đơn vị từ vựng này có vai trò quan trọng trong tiếng Pháp. Chúng tôi hoàn toàn nhất trí đưa nội dung này vào đề thi tuyển sinh đại học.

- Tất cả các từ đều thuộc nhóm từ vựng thông dụng phần lớn xuất hiện trong chương trình giảng dạy tiếng Pháp ở trường phổ thông. Tất nhiên, nếu chỉ biết nghĩa của từ thì chưa đủ để trả lời câu hỏi vì các từ này luôn được đặt trong ngữ cảnh. Thí sinh phải nắm vững 
cách dùng của các từ khác trong câu ; nhưng các từ này thường nằm trong cùng trường nghĩa với từ déclencheur trong câu hỏi và từ dùng để trả lời.

• Về tính từ và trạng từ, bảng thống kê cho thấy hai loại từ này xuất hiện thường xuyên trong các đề. Tính từ có số lượng lớn hơn trạng từ. Quan hệ giữa tính từ và trạng từ cũng được kiểm tra trong các CT về cấu tạo trạng từ. Thí dụ: 53(14) L'adverbe qui vient de l'adjectif fort est ----(fortuitement fortement forcément formellement). Ta biết rằng trạng từ có cấu tạo theo quy tắc chung là “adjectif féminin + ment", nhưng có những trường hợp ngoại lệ: joli $\rightarrow$ joliment, violent $\rightarrow$ violemment. Các tác giả đã đưa nhiều tính từ có cấu tạo đặc biệt vào các đề. Thí dụ: absolument(09), bruyamment(10), forcément(14), gentiment(09), joliment(13).

Như vậy về tổng thể nội dung từ vựng trong các đề thi là phù hợp cả về số lượng và về ngữ nghĩa. Tuy nhiên chúng tôi có một lưu ý liên quan đến "sự hợp giống, số" của một số danh từ sử dụng như tính từ và các tính từ kép. Cách dùng những trường hợp đặc biệt này không dễ. Đây là một khó khăn không chỉ đối với người nước ngoài mà còn với nhiều người Pháp bản ngữ (Nouailhac, 2006), nhưng nội dung này lại xuất hiện ở nhiều đề thi: bleu clair (13), bleu marine (11), bleu vert (08) gris clair (14) vert foncé (07) (12). Chúng tôi cho rằng không nên sử dụng các "bẫy” khó như vậy, hơn nữa hiện tượng ngữ pháp này không có trong chương trình giảng dạy tiếng Pháp ở trường phổ thông Việt Nam.

\section{3. Đọc hiểu}

Đọc hiểu chiếm một vị trí quan trọng trong dạy-học ngoại ngữ, và do vậy nó xuất hiện trong hầu hết các kỳ thi tuyển ngoại ngữ. Điểm xuất phát của việc kiểm tra kỹ năng này là một bài khóa. Sau đây là các thông số chính (chủ đề, loại văn bản, nguồn, số từ của bài và số lượng câu hỏi) của các tài liệu đã được sử dụng trong 10 đề thi.

Bảng 3. Nội dung đọc hiểu

\begin{tabular}{|c|c|c|c|c|}
\hline Năm & Đầu đề & Dạng văn bản & Nguồn & $\begin{array}{l}\text { Số lượngtừ } \\
\text { - câu hỏi }\end{array}$ \\
\hline 2005 & (sans titre) & Informatif & & $217-5$ \\
\hline 2006 & $\begin{array}{l}\text { Les conséquences de la } \\
\text { pollution de l'eau }\end{array}$ & Informatif & $\begin{array}{l}\text { D'après CARISSONI. Les Clés de } \\
\text { l'actualité junior, no } 230 \text { du } 6 \text { au } 12 \text { janvier } \\
2000\end{array}$ & $158-8$ \\
\hline 2007 & $\begin{array}{l}\text { - Le repas en } 2020 \\
\text { - (sans titre) }\end{array}$ & Informatif & & $\begin{array}{l}242-10 \\
227-10 \\
\end{array}$ \\
\hline 2008 & $\begin{array}{l}\text { - Les Français à table } \\
\text { - Moins polluer }\end{array}$ & Informatif & $\begin{array}{c}\text { G. Mermet, Francoscopie, Éd. Larousse, } \\
\text { 1989. Sciences et vie junior, } N^{o} 190 \text {, } \\
\text { juillet } 2005\end{array}$ & $\begin{array}{l}242-10 \\
127-10\end{array}$ \\
\hline 2009 & $\begin{array}{c}\text { J'exerce une profession } \\
\text { libérale dans une grande } \\
\text { entreprise }\end{array}$ & Narratif & & $233-10$ \\
\hline 2010 & Tour de France 2003 & Informatif & Pierre Lepidi, Le Monde, 26 octobre 2002. & $254-10$ \\
\hline 2011 & Facebook et les études & Informatif & D'après lefigaro.fr, 24/05/2009 & $330-10$ \\
\hline 2012 & $\begin{array}{c}\text { Rentrée } 2011: \text { cours le } \\
\text { matin, sport l'après-midi? }\end{array}$ & Informatif & $\begin{array}{l}\text { Par Bénédicte Boucays, lesclesjunior.com, } \\
\qquad 31 \text { mai } 2011\end{array}$ & 291-10 \\
\hline 2013 & \begin{tabular}{|c|} 
Un continent de déchets \\
en plastique dans l'Océan
\end{tabular} & Informatif & D'après lesclesjunior.com, 9 mars 2010 & $331-10$ \\
\hline 2014 & $\begin{array}{l}\text { La pratique du vélo se } \\
\text { développe en France }\end{array}$ & Informatif & D'après AFP, lepoint.fr, le 29/05/2013 & 414-10 \\
\hline
\end{tabular}


Từ đó, chúng tôi có những nhận xét sau:

- Tiêu đề và nguồn của tài liệu là những thông tin rất quan trọng trong đọc hiểu vì chúng giúp người đọc định hướng nội dung của bài. Chúng tôi thấy có những khoảng trống trong bảng trên: các năm 2005 và 2007 (bài khóa số 2) không có tiêu đề; các năm 2005, 2007 và 2009 thiếu nguồn tài liệu. Đây là điều đáng tiếc.

- Dựa trên các tiêu đề và nội dung, có thể xếp các văn bản vào năm chủ đề: y tế $(05)$ (07), thể thao (10) (14), nghề nghiệp (09), giáo dục (11) (12), môi trường (06) (08) (13). Chúng tôi cho rằng việc lựa chọn như vậy là phù hợp vì tất cả đều là những lĩnh vực thường gặp trong cuộc sống hàng ngày. Hơn nữa, hầu hết các tài liệu đều là mang tính thông tin là chủ yếu (texte à dominante informative) dễ dàng tiếp cận.

- Độ dài bài khóa và số lượng câu hỏi cũng cần được chú ý. Số lượng câu hỏi dao động từ 5 đến 20 , kỷ lục thuộc về những năm 2007 và 2008 với 20 câu hỏi cho 2 bài khóa; kể từ năm 2009 đề thi ổn định ở mức 10 câu hỏi. Độ dài tài liệu cũng dao động: 158 từ năm 2006 và 414 từ năm 2014 (theo thống kê trên máy tính). Về nội dung các câu hỏi, hầu hết chỉ dừng ở các ý tường minh được tác giả đưa ra một cách rõ ràng. Thiếu các câu hỏi suy luận về thông tin ẩn mà thí sinh phải huy động năng lực tư duy của mình để tìm ra (Morissette, 1996).

- Chúng tôi cho rằng nên thực hiện kỹ năng đọc hiểu bằng hai bài khóa: bài thứ nhất có độ dài 150-250 từ thuộc thể loại thông báo, nội dung tường minh và được kiểm tra thông qua $10 \mathrm{CT}$ chủ yếu về từ vựng; bài thứ hai có độ dài 250-350 từ và $10 \mathrm{CT}$, thể loại thiên về lập luận, nội dung khó hơn đòi hỏi năng lực suy diễn.

\subsection{Ngôn ngũu nói trong tình huống}

Trong tất cả các đề đều có sự xuất hiện của "ngôn ngữ nói trong tình huống" theo nghĩa đã nêu trong 1.4. Chúng tôi cho rằng đây là điểm đáng ghi nhận vì như vậy kiến thức liên quan đến kỹ năng diễn đạt nói đã được kiểm tra. Trong khi chúng ta không thể kiểm tra nói trực tiếp (face à face) thì việc yêu cầu thí sinh đưa ra một hành vi ngôn ngữ phù hợp trong một bài hội thoại ngắn và/hoặc một tình huống giao tiếp là một cách làm hay.

Điều cần lưu chú ý ở đây là tỷ lệ và nội dung của mảng kiến thức này. "Ngôn ngữ nói trong tình huống" chỉ chiếm trung bình 5,54\% các $\mathrm{CT}$, một con số quá thấp so với $75 \%$ của “ngữ pháp" và "từ vựng". Nếu nội dung của phần kiểm tra này chỉ có hai dạng câu hỏi như đã nêu ở 1.4. thì quá ít: cần tiếp tục suy nghĩ để có các dạng khác, và dành một mục riêng cho kỹ năng nói như đối với kỹ năng đọc hiểu. Đây là điều cần làm trong thời gian tới.

\section{Một số đề nghị}

Các phân tích trên có thể làm cơ sở cho việc xây dựng định dạng và xác định nội dung của đề thi "đánh giá năng lực". Dưới đây là một số đề nghị của chúng tôi:

a) Nếu các đề thi trước đây chỉ nhằm mục đích tuyển sinh, thì đề thi trong giai đoạn mới có nhiệm vụ "đánh giá năng lực" của thí sinh. Nói cách khác, đề thi không giới hạn ở việc đánh giá thí sinh đỗ hay trượt mà còn cần có tính phân loại. Cơ sở phân loại là Khung năng lực ngoại ngữ 6 bậc dùng cho Việt Nam (BGDĐT, 2014), trong đó, yêu cầu về năng lực ngôn ngữ và giao tiếp của từng cấp độ đã được xác định rõ ràng. Do vậy, nội dung của đề thi cần trải dài từ bậc $\mathrm{A} 1$ đến $\mathrm{C} 1$. Kết quả làm bài cho phép phân loại thí sinh từ đó định hướng việc dạy/học sau khi xét tuyển. 
b) Với thời lượng làm bài 90 phút, việc quy định $80 \mathrm{CT}$ cho mỗi đề từ nhiều năm nay theo chúng tôi là phù hợp. Về nội dung kiểm tra, chúng tôi đề xuất thêm phần $n g \tilde{u}$ âm vốn là một thành tố quan trọng của ngôn ngữ, và kiến thức liên quan đến diễn đạt viết. Cơ cấu của đề có thể là: Ngữ âm $(5 \mathrm{CT})$, Từ vựng (15 CT), Ngữ pháp (20 CT), Ngôn ngữ nói trong tình huống $(10 \mathrm{CT})$, Kiến thức liên quan đến diễn đạt viết (10 CT), Đọc hiểu (20 CT). Câu hỏi về ba nội dung cuối (liên quan đến ba kỹ năng giao tiếp nói, viết, đọc) cần được đa dạng hơn các đề thi trước đây.

c) Để thuận lợi cho việc biên soạn đề thi, cần xây dựng một bảng đặc tả. Trong đó mỗi $\mathrm{CT}$ hoặc nhóm $\mathrm{CT}$ cần được cung cấp ba thông tin: nội dung kiểm tra, dạng thức câu hỏi và bậc kiến thức theo CECR. Bảng đặc tả phải bao quát toàn bộ kiến thức cần đánh giá, như vậy đề thi không bỏ sót một số nội dung tránh sự "mất cân đối" mà chúng tôi đã nêu ra trong quá trình phân tích.

d) Loại câu hỏi đa lựa chọn có một lợi thế rất lớn. Một mặt, nó cho phép kiểm tra nhiều nội dung trong một thời gian ngắn, mặt khác nó loại bỏ tính chủ quan trong việc chấm bài (Jacobs, 2004). Dạng câu hỏi này cần được sử dụng triệt để mặc dù chúng có một số hạn chế trong việc kiểm tra kỹ năng diễn nói và viết. Tránh dạng câu hỏi truyền thống yêu cầu thí sinh viết câu trả lời (Thí dụ, Chia động từ trong ngoặc ở dạng thức thích hợp: 12 (05) Mes parents insistent pour que je (faire) des études en médecine.) Nếu có thể tổ chức làm bài thi trên máy tính.

e) Đề thi tuyển sinh của Trường Đại học Ngoại ngữ - Đại học Quốc gia Hà Nội nên gắn với thực tế Việt Nam, và nếu có thể với thực tế của Trường. Có thể là thông tin chung về nhà trường hoặc các thông tin hữu ích cho thí sinh. Ví dụ: "On peut se rendre à l'UNH en bus, le 32, le 49... passent devant." (Bạn có thể đi đến Đại học Quốc gia bằng xe buýt, xe 32, xe 49 ... đi qua trước của Truờng). Một câu như vậy có thể được sử dụng để đánh giá nhiều hiện tượng ngôn ngữ như: cú pháp, động từ, từ đồng nghĩa, giới từ, từ vựng về phương tiện đi lại..., đồng thời là một chỉ dẫn rất thực tế cách đi đến Trường.

f) Cuối cùng cần chú ý tới nội dung "tư tưởng” của các CT. Đề thi cần góp phần giáo dục thế hệ trẻ, do vậy nên tránh những câu có tính phân biệt xã hội như 51 (2014): Je n'épouserai pas ce garçon! Je ne veux pas finir ma vie à la campagne. - Justement. Tu y es née ! (Tôi sẽ không lấy anh con trai ấy! Tôi không muốn kết thúc đời mình ở nông thôn. - Đúng vậy. Cậu đã sinh ra ở đó mà !). Đành rằng, có thể hiểu câu trả lời có tính mỉa mai, phản bác lại quan điểm của cô gái, nhưng dầu sao những câu như vậy cũng có khả năng gây tổn thương, nhất là đối với những thí sinh từ nông thôn.

Tuyển sinh thông qua một kỳ thi đánh giá năng lực là một chủ trương hết sức đúng đắn. Đây là một công việc lớn bao gồm nhiều công đoạn, trong đó có việc thiết kế và biên soạn đề thi. Chúng tôi hy vọng những kết quả phân tích và các đề nghị ở trên sẽ một phần giúp ích cho việc thực hiện chủ trương này của Đại học Quốc gia Hà Nội.

\section{Tài liệu tham khảo}

\section{Tiếng Việt}

Bộ Giáo dục và Đào tạo, Khung năng lục ngoại ngũ 6 bậc dùng cho Việt Nam, Thông tư số 01/2014/TT - BGDĐT. 


\section{Tiếng Pháp}

Dubois et al, Dictionnaire de linguistique, Larousse, 1973, réédité en 1994.

Grevisse M., Le bon usage, $14^{\mathrm{e}}$ éd. par André Goosse, Louvain-la-Neuve, Duculot, 2007.

Jacobs L.-C., How to Write Better Tests: A Handbook

for Improving Test Construction Skills, Bloomington, Indiana University, 2004.
Morissette D., Guide pratique de l'évaluation sommative. Gestion des épreuves et des examens, Montréal: éditions du renouveau pédagogique, 1996.

Nouailhac I., Le pluriel de bric-à-brac et autres difficultés de la langue française, Paris, Seuil, 2006.

\title{
A CRITICAL REVIEW OF THE UNIVERSITY ENTRANCE TESTS OF THE FRENCH LANGUAGE IN THE 2005-2014 PERIOD
}

\author{
Nguyen Viet Quang \\ Faculty of French Language and Culture, VNU University and Languages and International \\ Studies, Pham Van Dong, Cau Giay, Hanoi, Vietnam
}

\begin{abstract}
With the aim of having a well-prepared French-language proficiency test for reformed university entrance exam, there arises a critical need to research into existing tests. Hence, this paper has studied ten French-language proficiency tests in the 2005-2014 period. The objectives are to perceive strengths and "imbalances" of the test structure and content. It is a three-phase procedure starting with an identification of the linguistic and communicative areas of tested tasks and items, then doing a detailed analysis of each area, and finally presenting recommendations to improve the test design process.

Keywords: university entrance exam, knowledge area, assessment, French-language proficiency test
\end{abstract}




\section{PHỤ LỤC \\ BẢNG THỐNG KÊ TÙ VỤ̂NG}

(chữ số trong ngoặc đơn chỉ "năm" của đề thi)

\begin{tabular}{|c|c|c|c|c|}
\hline 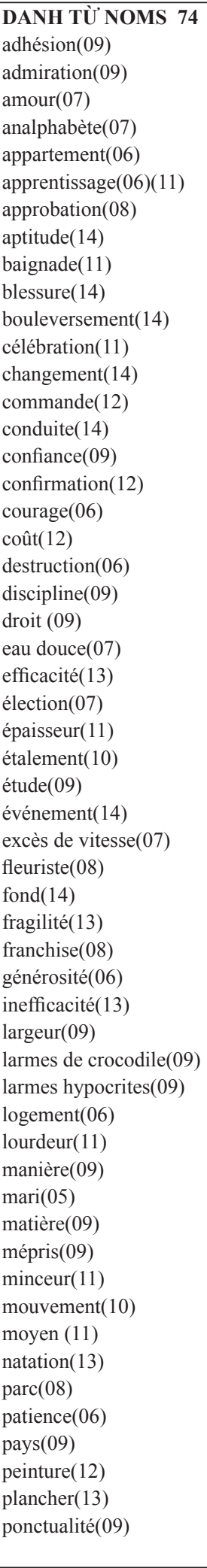 & 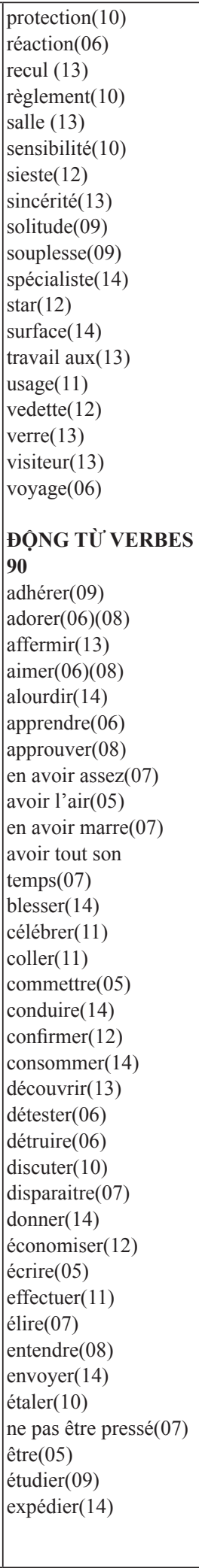 & $\begin{array}{l}\text { explorer(13) } \\
\text { faire(05)(12) } \\
\text { fonctionner(10) } \\
\text { gaspiller(12) } \\
\text { ignorer(08) } \\
\text { s'installer(08) } \\
\text { laisser(10) } \\
\text { mesurer(05) } \\
\text { mettre en place(09) } \\
\text { mûrir(10) } \\
\text { nager(13) } \\
\text { nettoyer(05) } \\
\text { offrir(05) } \\
\text { oublier(10) } \\
\text { se pencher(09) } \\
\text { permettre(11) } \\
\text { peser(05) } \\
\text { plaire(06) } \\
\text { pratiquer(05) } \\
\text { prendre l'air (08) } \\
\text { prêter(06)(09) } \\
\text { prévoir(11) } \\
\text { produire(05)(14) } \\
\text { programmer(11) } \\
\text { se prononcer sur (07) } \\
\text { protéger(10) } \\
\text { provoquer(07) } \\
\text { raccourcir(12) } \\
\text { raconter(14) } \\
\text { rajeunir(09) } \\
\text { ralentir(07) } \\
\text { se rappeler(10) } \\
\text { rappeler(11) } \\
\text { réagir(06) } \\
\text { réaliser(11) } \\
\text { reculer(13) } \\
\text { regretter (07) } \\
\text { remédier(09) } \\
\text { remplacer(10)(13) } \\
\text { répondre(05) } \\
\text { retirer(11) } \\
\text { savoir(08) } \\
\text { se serrer la main(13) } \\
\text { sortir(08) } \\
\text { substituer(10) } \\
\text { susciter(07) } \\
\text { tranquilliser(13) } \\
\text { travailler(09) } \\
\text { user(11) } \\
\text { verdir(08) } \\
\text { verser(11) } \\
\text { vivre(09) } \\
\text { voir la vie en rose(07) } \\
\text { voir tout en gris(07) }\end{array}$ & 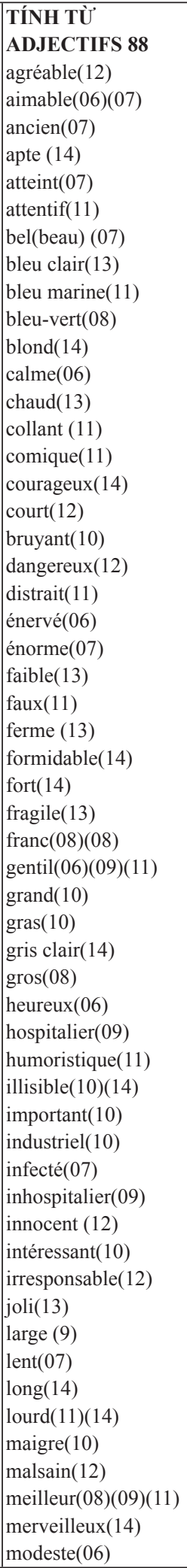 & $\begin{array}{l}\text { mûr(10) } \\
\text { noir(12) } \\
\text { nouveau (12) } \\
\text { nuisible(09) } \\
\text { nul(14) } \\
\text { orgueilleux(06) } \\
\text { ouvert(08) } \\
\text { pauvre femme(06) } \\
\text { pénible(12) } \\
\text { petit(08) } \\
\text { peureux(14) } \\
\text { pollué(09)(11) } \\
\text { ponctuel(09) } \\
\text { prêt(06) } \\
\text { prochain(06)(08)(13) } \\
\text { pur(09) } \\
\text { rouge(07) } \\
\text { sain(12) } \\
\text { sale(12) } \\
\text { salé(12) } \\
\text { sensible(10) } \\
\text { seul(09) } \\
\text { solide(13) } \\
\text { souple(09) } \\
\text { toxique(12) } \\
\text { tranquille(13) } \\
\text { turc(11) } \\
\text { vert foncé(07)(12) } \\
\text { vert(08) } \\
\text { vide(08) } \\
\text { vif(11) } \\
\text { violent(12) } \\
\text { vrai (12) } \\
\text { teullement(14) } \\
\text { TRÀ fait(09) } \\
\text { tout de suite(09) } \\
\text { violemment(12) } \\
\text { vivement(11) } \\
\text { progrécisément(09) } \\
\text { ADVERBivement(13) } \\
\text { à cœur ouvert (13) } \\
\text { absolument(09) } \\
\text { brusquement(10)(13) } \\
\text { bruyamment(10) } \\
\text { efficacement(12) } \\
\text { également(11) } \\
\text { exactement(09) } \\
\text { facilement(13) } \\
\text { forcément(14) } \\
\text { fortement(14) } \\
\text { gentiment(09) } \\
\text { joliment(13) } \\
\text { longuement(09) }\end{array}$ \\
\hline
\end{tabular}

